\title{
Posthitis in Circumcised Child: A Condition Not Previously Reported in the Literature
}

\section{Aamir Jalal Al-Mosawi ${ }^{1,2}$}

${ }^{1}$ Advisor in Pediatrics and Pediatric Psychiatry, Children Teaching Hospital of Baghdad Medical City, Iraq. ${ }^{2}$ Advisor doctor, The National Training and development Center of the Iraqi Ministry of Health, Baghdad, Iraq. *Corresponding Author: Aamir Jalal Al-Mosawi, Advisor in Pediatrics and Pediatric Psychiatry, Children Teaching Hospital of Baghdad Medical City, Iraq.

\section{Abstract}

Background: Posthitis, an inflammation of the prepuce of the penis is associated with swelling and other inflammatory changes such as redness, itching, tenderness, and pain. It may occur in association with an inflammation of the glans penis, and in this case it is called balanoposthitis. Balanoposthitis has been reported only in uncircumcised males. Posthitis has not been reported in circumcised children. Balanoposthitis can be caused by bacteria, viruses, and fungi.

Patients and Methods: The case of a boy who revered a diagnosis of cellulites of the penis and scrotum was studied. The boy was circumcised and aged four years. He presented with fever, generalized erythematous macular rash, poor appetite, and swelling of the foreskin of the penis and scrotum. The boy was referred by the treating physician after poor response to eight days of the treatment, and the inability to determine the infective organism and the best antimicrobial agents to use.

Results: The diagnosis of posthitis of undetermined etiology was made. It was recommended to treat the boy with cefprozil and oral nystatin based on the evidence provided by Dockerty and Sonnex (1995) and Wakiguchi al (1992), or cefpodoxime proxetil plus nystatin, or cefixime plus nystatin based on the evidence provided by Schatz et al (1996). Thereafter, it was reported that the boy was improved.

Conclusion: When a condition is encountered for the first time, and there is no available experience in the medical literature, it can be useful to treat the condition with empiric therapies based on the evidence provided from the more relevant literature.

Keywords: Posthitis, circumcised child, novel occurrence.

\section{INTRODUCTION}

Posthitis, an inflammation of the prepuce of the penis is associated with swelling and other inflammatory changes such as redness, itching, tenderness, and pain. It may occur in association with an inflammation of the glans penis, and in this case it is called balanoposthitis. Balanoposthitis has been reported only in uncircumcised males. The definitive treatment of both conditions is circumcision. Posthitis has not been reported in circumcised children. Balanoposthitis can be caused by bacteria, viruses, and fungi [1].

\section{Patients And Methods}

The case of a boy who revered a diagnosis of cellulites of the penis and scrotum was studied. The boy was circumcised and aged four years. He presented with fever, generalized erythematous macular rash, poor appetite, and swelling of the foreskin of the penis and scroum. The boy was referred by the treating physician after poor response to eight days of the treatment, and the inability to determine the infective organism and the best antimicrobial agents to use. When the boy was seen he was still having fever, anorexia, and generalized skin rash affecting the trunk and limbs (Figure-1). The boy also still having swelling of the prepuce and scrotum (Figure-2). The boy didn't have obvious inflammation of the glans penis, balanitis. 


\section{Posthitis in Circumcised Child: A Condition Not Previously Reported in the Literature}

The boy was initially treated with oral amoxicillin for three days followed by oral azithromycin for an other three days. Thereafter, he was hospitalized because of marked anorexia and poor response to treatment. He received intravenous fluids, and was treated with intravenous amoxicillin (500 mg three times daily) for two days. Blood for culture was taken few days after the start of antibiotic therapy didn't reveal the infective organism. ASO titer was negative, but C-reactive protein was positive at the level of $48 \mathrm{mg} / \mathrm{L}$.
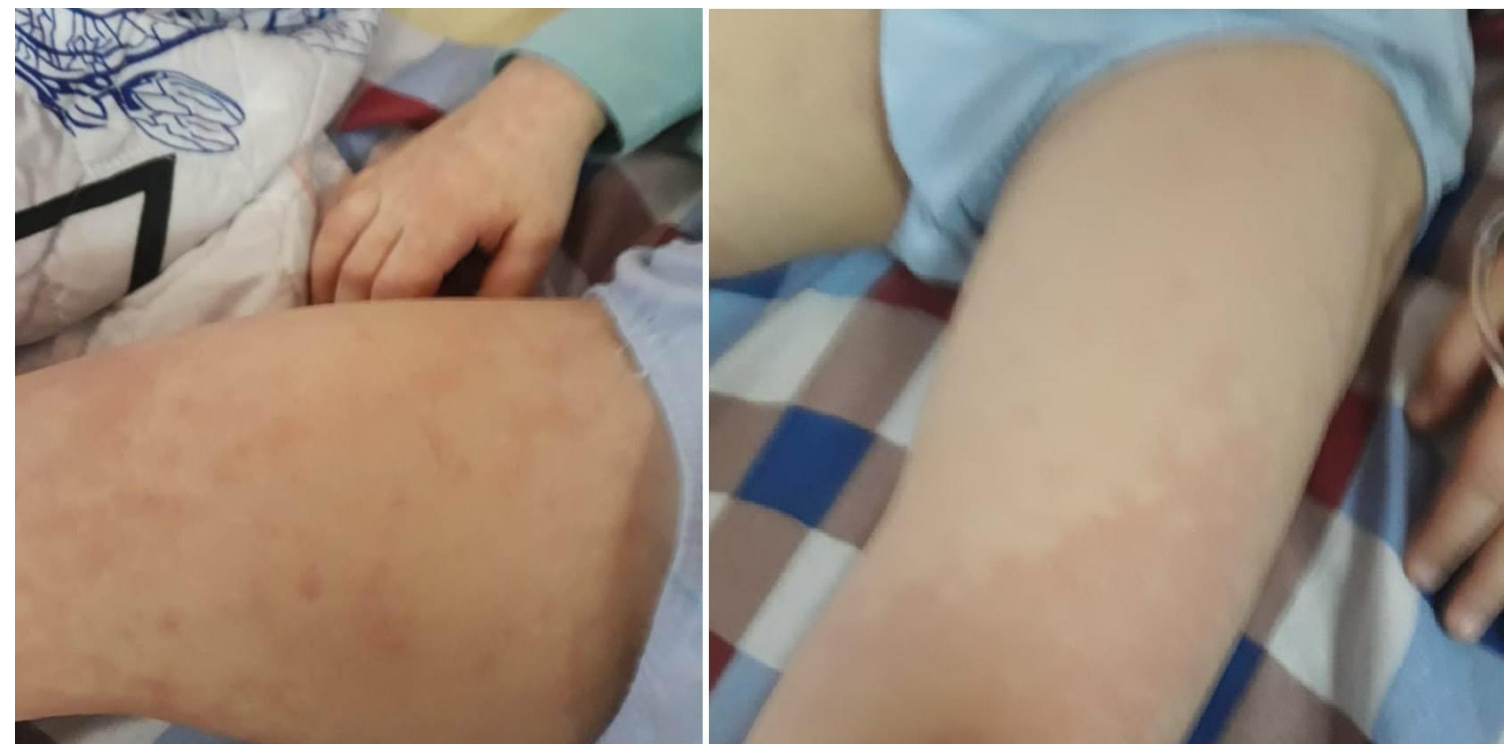

Figure1. After eight days of treatment, the boy was still having generalized skin rash affecting the trunk and limbs

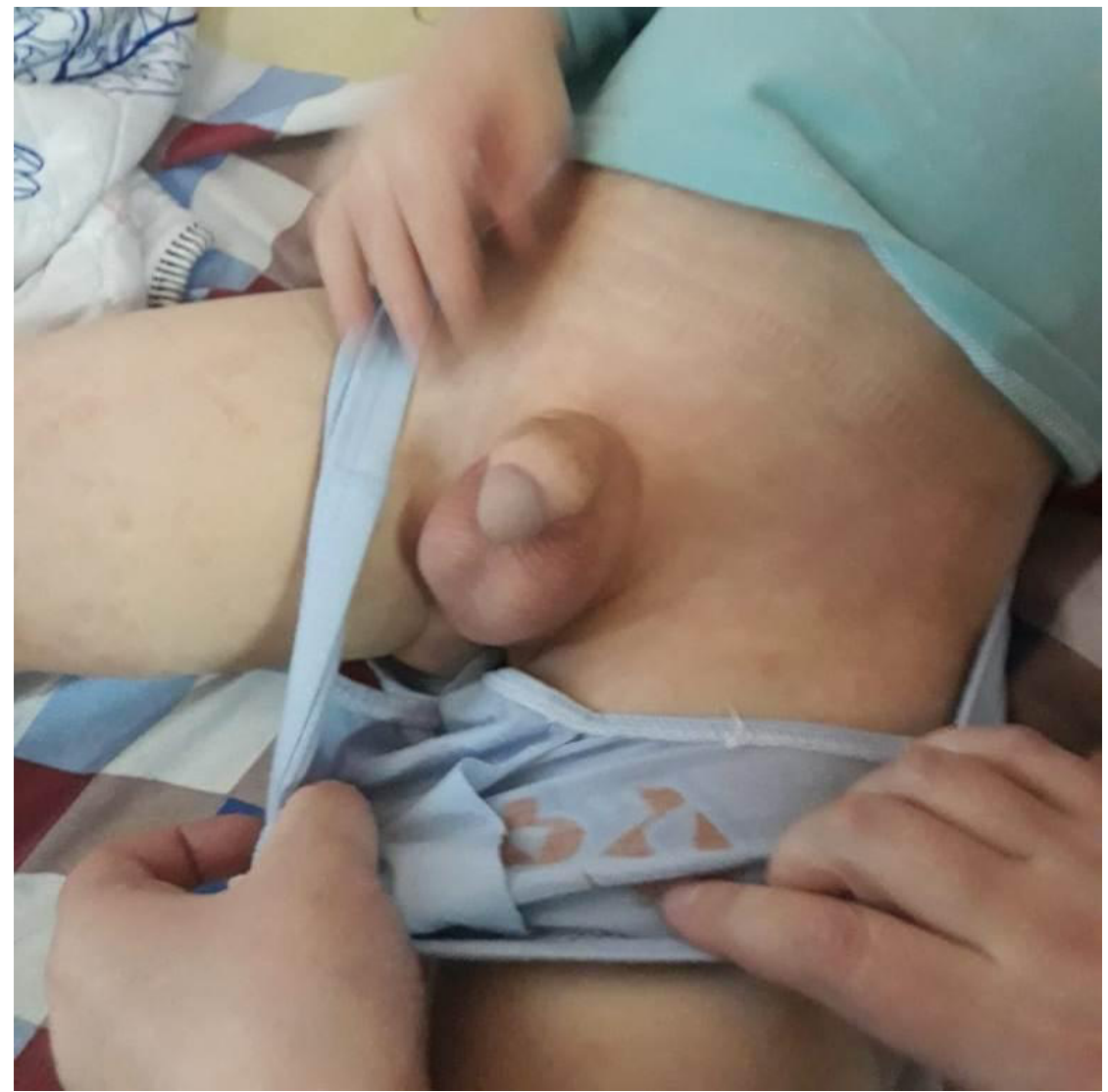

Figure2. After eight days of treatment, the boy was still having swelling of the prepuce and scrotum 
Posthitis in Circumcised Child: A Condition Not Previously Reported in the Literature

\section{RESULTS}

The diagnosis of posthitis of undetermined etiology was made. It was recommended to treat the boy with cefprozil and oral nystatin based on the evidence provided by Dockerty and Sonnex (1995) and Wakiguchi al (1992) [1,2], or cefpodoxime proxetil plus nystatin, or cefixime plus nystatin based on the evidence provided by Schatz etal (1996) [3]. Thereafter, it was reported that the boy was improved.

\section{DiscusSION}

Balanoposthitis has been reported only in uncircumcised males, and it can be caused by can be caused by bacteria, viruses, and fungi. Posthitis has not been reported in circumcised children, and the is no published experience regarding its etiology or treatment [1.2].

Dockerty and Sonnex (1995) reported that candida was isolated from $35 \%$ of 450 males with balanoposthitis observed a three year period [1].

Wakiguchi al (1992) studied the therapeutic effects of cefprozil, a new cephalosporin in a variety of childhood infectious diseases in children. Clinical efficacy was $100 \%$ in 8 patients having impetigo contagiosa, furuncle and posthitis [2].

Schatz et al (1996) examined the antibacterial activity, and adverse events of cefprozil, cefpodoxime proxetil, and, cefixime by reviewing the literature published during the period from 1986 to January 1995. They found that cefprozil, cefpodoxime, and cefixime showed in vitro activity against most bacteria causing community-acquired infections. They recommended that the choice of a specific agent is mostly determined by susceptibility data and cost [3].

Lisboa et al (2009) emphasized that the treatment of balanoposthitis is commonly challenging [4].

\section{CoNCLUSION}

When a condition is encountered for the first time, and there is no available experience in the medical literature, it can be useful to treat the condition with empiric therapies based on the evidence provided from the more relevant literature.

\section{REFERENCES}

[1] Dockerty WG, Sonnex C. Candidal balanoposthitis: a study of diagnostic methods. Genitourin Med. 1995 Dec; 71(6):407-9.Doi: 10.1136/sti.71.6.407. PMID: 8566986.

[2] Wakiguchi H, Ohishi N, Kido S, Takechi T, Takeda K, Yoshimura K, Nomura I, Fujieda M, Araki K, Kurashige T. Therapeutic effects of cefprozil in the treatment of various infectious diseases in children]. Jpn J Antibiot 1992 Dec; 45(12):167683. Japanese. PMID: 1289587[Article in Japanese].

[3] Schatz BS, Karavokiros KT, Taeubel MA, Itokazu GS. Comparison of cefprozil, cefpodoxime proxetil, loracarbef, cefixime, and ceftibuten. Ann Pharmacother 1996 Mar; 30(3):258-68. PMID: 8833562.Doi: 10.1177/106002809603000310.

[4] Lisboa C, Ferreira A, Resende C, Rodrigues AG. Infectious balanoposthitis: management, clinical and laboratory features. Int J Dermatol $2009 \mathrm{Feb}$; 48(2):121-4. PMID: 19200183. Doi: 10.1111/ j.1365-4632.2009.03966.x

Citation: Aamir Jalal Al-Mosawi. Posthitis in Circumcised Child: A Condition Not Previously Reported in the Literature. Archives of Urology. 2020; 3(2): 16-18.

Copyright: (C) 2020 Aamir Jalal Al-Mosawi. This is an open access article distributed under the Creative Commons Attribution License, which permits unrestricted use, distribution, and reproduction in any medium, provided the original work is properly cited. 